\title{
Errata
}

Pseudonocardia adelaidensis sp. nov., an endophytic actinobacterium isolated from the surface-sterilized stem of a grey box tree (Eucalyptus microcarpa)

Onuma Kaewkla and Christopher M. M. Franco

International Journal of Systematic and Evolutionary Microbiology (2010), 60, part 12, 2818-2822.

The type strain of Pseudonocardia adelaidensis is EUM 221, as given in the abstract, not EUM 211, as given in the description of the species.

doi:10.1099/ijs.0.67541-0

\section{Pontibacter niistensis sp. nov., isolated from forest soil}

Syed G. Dastager, O. S. Raziuddin, C. K. Deepa, Wen-Jun Li and Ashok Pandey

International Journal of Systematic and Evolutionary Microbiology (2010), 60, part 12, 2867-2870.

The type strain of Pontibacter niistensis is NII-0905, as given in the abstract, not NII-0909, as given in the description of the species.

doi:10.1099/ijs.0.67571-0 